\title{
Prognostic value of alcohol dehydrogenase mRNA expression in gastric cancer
}

\author{
ERNA GUO ${ }^{1,2^{*}}$, HAOTANG WEI ${ }^{3 *}$, XIWEN LIAO ${ }^{4}$, YANG XU $^{1}$, SHU LI $^{1}$ and XIAOYUN ZENG ${ }^{1}$ \\ ${ }^{1}$ School of Public Health; ${ }^{2}$ School of International Education, Guangxi Medical University, \\ Nanning, Guangxi Zhuang Autonomous Region 530021; ${ }^{3}$ Department of Gastrointestinal Surgery, \\ The Third Affiliated Hospital of Guangxi Medical University, Nanning, Guangxi Zhuang Autonomous Region 530031; \\ ${ }^{4}$ Department of Hepatobiliary Surgery, The First Affiliated Hospital of Guangxi Medical University, \\ Nanning, Guangxi Zhuang Autonomous Region 530021, P.R. China
}

Received June 30, 2017; Accepted December 8, 2017

DOI: $10.3892 / \mathrm{ol} .2018 .8007$

\begin{abstract}
Previous studies have reported that alcohol dehydrogenase $(\mathrm{ADH})$ isoenzymes possess diagnostic value in gastric cancer (GC). However, the prognostic value of $\mathrm{ADH}$ isoenzymes in GC remains unclear. The aim of the present study was to identify the prognostic value of $\mathrm{ADH}$ genes in patients with GC. The prognostic value of $\mathrm{ADH}$ genes was investigated in patients with GC using the Kaplan-Meier plotter tool. Kaplan-Meier plots were used to assess the difference between groups of patients with GC with different prognoses. Hazard ratios (HR) and $95 \%$ confidence intervals (CI) were used to assess the relative risk of GC survival. Overall, 593 patients with GC and $7 \mathrm{ADH}$ genes were included in the survival analysis. High expression of ADH 1A (class 1), $\alpha$ polypeptide $(A D H 1 A$; log-rank $\mathrm{P}=0.043 ; \mathrm{HR}=0.79 ; 95 \% \mathrm{CI}$ : $0.64-0.99)$, ADH 1B (class 1$), \beta$ polypeptide $(A D H 1 B$; log-rank $\left.\mathrm{P}=1.9 \times 10^{-05} ; \mathrm{HR}=0.65 ; 95 \% \mathrm{CI}: 0.53-0.79\right)$ and ADH 5 (class III), $\chi$ polypeptide $(A D H 5$; log-rank $\mathrm{P}=0.0011 ; \mathrm{HR}=0.73$; 95\% CI: 0.6-0.88) resulted in a significantly decreased risk of mortality in all patients with GC compared with patients with low expression of those genes. Furthermore, protective effects may additionally be observed in patients with intestinal-type $\mathrm{GC}$ with high expression of $A D H 1 B$ (log-rank $\mathrm{P}=0.031 ; \mathrm{HR}=0.64 ; 95 \% \mathrm{CI}$ : 0.43-0.96) and patients with diffuse-type $\mathrm{GC}$ with high expression of $A D H 1 A$ (log-rank $\mathrm{P}=0.014 ; \mathrm{HR}=0.51 ; 95 \% \mathrm{CI}: 0.3-0.88), A D H 1 B$ (log-rank $\mathrm{P}=0.04 ; \mathrm{HR}=0.53 ; 95 \% \mathrm{CI}: 0.29-0.98), \mathrm{ADH} 4$ (class II), $\pi$ polypeptide $(\log -\operatorname{rank} \mathrm{P}=0.033$; $\mathrm{HR}=0.58 ; 95 \% \mathrm{CI}$ :
\end{abstract}

Correspondence to: Professor Xiaoyun Zeng, School of Public Health, Guangxi Medical University, 22 Shuang Yong Road, Nanning, Guangxi Zhuang Autonomous Region 530021, P.R. China E-mail: zxyxjw@21cn.com

*Contributed equally

Key words: prognosis, expression, alcohol dehydrogenase, gastric cancer, Kaplan-Meier plotter
0.35-0.96) and ADH 6 (class V) (log-rank $\mathrm{P}=0.037 ; \mathrm{HR}=0.59$; $95 \% \mathrm{CI}$ : 0.35-0.97) resulting in a significantly decreased risk of mortality compared with patients with low expression of those genes. In contrast, patients with diffuse-type GC with high expression of $A D H 5$ (log-rank $\mathrm{P}=0.044 ; \mathrm{HR}=1.66$; 95\% CI: 1.01-2.74) were significantly correlated with a poor prognosis. The results of the present study suggest that $A D H 1 A$ and $A D H 1 B$ may be potential prognostic biomarkers of $\mathrm{GC}$, whereas the prognostic value of other $\mathrm{ADH}$ genes requires further investigation.

\section{Introduction}

Gastric cancer (GC) is a stomach cancer with a particularly high incidence in China, and in 2015 was the second leading cause of cancer-associated mortality in China $(1,2)$. It has been estimated that in 2015 there were 498,000 GC-associated mortalities in China in 2015 (1). Not only is GC prevalent in China, patients also experience poor survival rates (with the age-standardized 5 -year relative survival rate being <30\%) (3). It is now known that GC is a disease that results from environmental and genetic factors and that Helicobacter pylori infection is the most notable risk factor, with alcohol consumption also potentially promoting the progression of GC (4-6). The link between alcohol and GC has been determined, however, the underlying molecular mechanism remains elusive $(7,8)$. Thus, the function of ethanol metabolism genes and signaling pathways in GC require further investigation.

Previous studies have reported that alcohol dehydrogenase $(\mathrm{ADH})$ genes are associated with upper aerodigestive types of cancer, and the genetic variation of the ADH cluster increases the risk of cancer for alcohol drinkers $(9,10)$. Furthermore, $\mathrm{ADH}$ isoenzymes additionally exhibit diagnostic value and prognostic prediction value in multiple different types of cancer (11-13). Total ADH isoenzyme activity is significantly increased in cancer tissues compared with healthy organs, and $\mathrm{ADH}$ isoenzymes possess diagnostic value for patients with GC (14,15). However, to the best of our knowledge, the prognostic value of $\mathrm{ADH}$ isoenzymes in GC have yet to be reported. The aim of the present study was to identify the prognostic value of $\mathrm{ADH}$ genes in patients with GC. 
Kaplan-Meier plotter (KM-plotter) (16) is an online survival analysis tool used to rapidly assess the effect of genes on the prognosis of four cancer types (breast, lung, ovarian and GC) using genome-wide microarrays from the Gene Expression Omnibus (GEO) and Cancer Biomedical Informatics Grid and The Cancer Genome Atlas (TCGA) (17-20). A previous study by $\mathrm{Li}$ et al (21) assessed the prognostic functions of $\mathrm{ADH}$ 1 family member A1 isoenzyme (another alcohol metabolism-associated isoenzyme) in GC using the KM-plotter tool, and identified that aldehyde dehydrogenase (ALDH) family member A3 and ALDH family member L1 were potential prognostic biomarkers and therapeutic targets for GC. In the present study, the KM-plotter tool was used to further investigate the prognostic prediction values of $\mathrm{ADH}$ genes in patients with GC.

\section{Materials and methods}

Bioinformatic analysis. Gene Ontology (GO) and Kyoto Encyclopedia of Genes and Genomes (KEGG) enrichment of ADH genes were analyzed using the Database for Annotation, Visualization and Integrated Discovery (david. ncifcrf.gov/home.jsp; accessed February 20, 2017) v.6.8 (22). Gene-gene and protein-protein interaction (PPI) networks were constructed using the gene multiple association network integration algorithm (GeneMANIA; genemania.org; accessed February 20,2017) $(23,24)$ and and the Search Tool for the Retrieval of Interacting Genes/Proteins (STRING v.10.0; string. embl.de; accessed February 20, 2017) $(25,26)$, respectively.

Data sources. KM-plotter datasets were obtained from GEO and TCGA (16). There were datasets available on the websites for four different types of cancer, including, breast, lung, ovarian and gastric cancer (16-20). In the present study, KM-plotter (kmplot.com/analysis/index.php?p= service\&cancer=gastric; accessed February 20, 2017) was used to identify the distinct prognostic values of ADH genes in GC (20). The clinical variables of GC, including Tumor-Node-Metastasis stage (Seventh edition) (27), tumor differentiation, Lauren classification (28), human epidermal growth factor receptor 2 (HER2) status and treatment were available on the websites. As the GSE52254 dataset was markedly different with regards to characteristics, compared with other GC datasets in the KM-plotter, it was excluded from the present study and the remaining five datasets were included for further investigation (GSE142210, GSE15459, GSE22377, GSE29272 and GSE51105) (20). Overall, the mRNA datasets of 593 patients with GC, with corresponding clinical data, were included in the survival analysis and a total of $7 \mathrm{ADH}$ genes were available on the KM-plotter website (kmplot.com/ analysis/index.php? $\mathrm{p}=$ service $\&$ cancer $=$ gastric; accessed February 20, 2017). The mRNA expression of the ADH genes in GC tumor and adjacent non-tumor tissues were used from the GSE29272 dataset (29), which included the expression data of 134 pairs of GC tumor and adjacent non-tumor tissue. The mRNA co-expression heat map of ADH genes was constructed from the mRNA expression of GC tumor tissues from the GSE29272 dataset. Microarray data were normalized using the RMA method, ( https://www.ncbi.nlm. nih.gov/geo/query/acc.cgi?acc=GSM723464).
Statistical analysis. Survival analysis in the KM-plotter tool used the Kaplan-Meier method with log-rank test, whereas the comparison of ADH genes mRNA expression between tumor and adjacent non-tumor used paired Student's t-tests. Hazard ratios (HR) and 95\% confidence intervals (CI) were used to assess the relative risk of GC survival. Pearson's correlation coefficient was used to assess the co-expression correlation at the mRNA expression level, and a co-expression heat map was constructed using the corrplot package in R 3.3.0 platform (30). Scatter plots were plotted using GraphPad Prism 6.0 (GraphPad Software, Inc., La Jolla, CA, USA). Statistical analyses were performed using SPSS v.20.0 software (IBM Corp., Armonk, NY, USA). $\mathrm{P}<0.05$ was considered to indicate a statistically significant difference.

\section{Results}

Bioinformatic analysis. GO analysis suggested that ADH genes [ADH 1A (class I), $\alpha$ polypeptide (ADH1A), ADH 1B (class I), $\beta$ polypeptide $(A D H 1 B)$, ADH $1 \mathrm{C}$ (class I), $\gamma$ polypeptide $(A D H I C), \mathrm{ADH} 4$ (class II), $\pi$ polypeptide $(A D H 4), \mathrm{ADH}$ 5 (class III), $\chi$ polypeptide (ADH5), ADH 6 (class V) $(A D H 6)$ and ADH 7 (class IV), $\mu$ or $\sigma$ polypeptide $(A D H 7)]$ were involved in ethanol oxidation, ADH activity, oxidoreductase activity, and alcohol and retinol metabolic processes (Fig. 1A). Whereas KEGG analysis of ADH genes indicated functions in tyrosine metabolism, retinol metabolism, glycolysis and gluconeogenesis, fatty acid degradation, drug metabolism via cytochrome $\mathrm{P} 450$ enzymes, metabolism of xenobiotics by cytochrome $\mathrm{P} 450$ enzymes and chemical carcinogenesis (Fig. 1B). GO and KEGG function enrichment analyses indicate that the ADH genes function in alcohol and toxic chemical metabolism, and participate in tumorigenesis.

Gene and protein interaction networks suggested that the ADH genes exist in a complex network associated with each other, with the exception of $A D H I C$ which was not recognized by GeneMANIA and STRING. Gene-gene interaction networks revealed that the ADH genes co-express with each other (Fig. 2A), whereas the PPI network data revealed that $\mathrm{ADH}$ isoenzymes were directly or indirectly associated with each other (Fig. 2B).

Survival analysis. By searching the GC database of the KM-plotter tool, only the GSE29272 dataset was revealed to have an mRNA dataset of GC tumor and adjacent non-tumor tissues. Consequently, only the GSE29272 dataset was used in order to compare GC tumor and adjacent non-tumor tissues. Due to missing data for $\mathrm{ADH} 4$ in the GSE29272 dataset, only six ADH genes were included in the comparison and co-expression heat map construction. ADH1A $(\mathrm{P}<0.001)$, ADHIB $(\mathrm{P}<0.001), A D H 1 C(\mathrm{P}<0.001)$ and $A D H 7(\mathrm{P}<0.001)$ exhibited significantly decreased expression in $\mathrm{GC}$ tumor tissue compared with non-tumor tissues, whereas $A D H 5$ was significantly upregulated $(\mathrm{P}=0.004)$ and $A D H 6$ demonstrated no significant difference $(\mathrm{P}=0.343)$ in tumor tissues compared with non-tumor tissues (Fig. 3A). Furthermore, all the ADH genes demonstrated a positive association with each other (Fig. 3B).

The valid gene Affymetrix ID of ADH genes in the KM-plotter tool were 207820_at (ADH1A; Fig. 4A-C), 

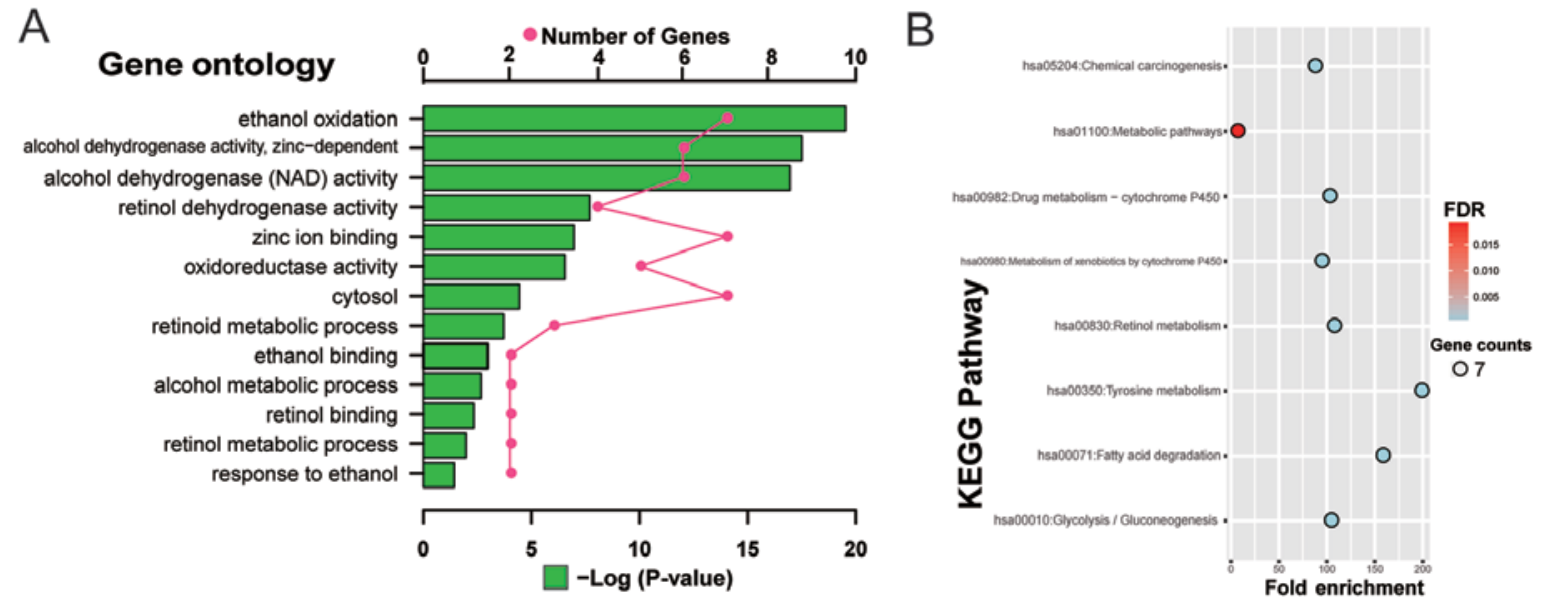

Figure 1. GO and KEGG analysis of ADH genes. (A) GO enrichment analysis of ADH genes. (B) KEGG enrichment analysis of ADH genes. GO, Gene Ontology; KEGG, Kyoto Encyclopedia of Genes and Genomes; ADH, alcohol dehydrogenase; FDR, false discovery rate.
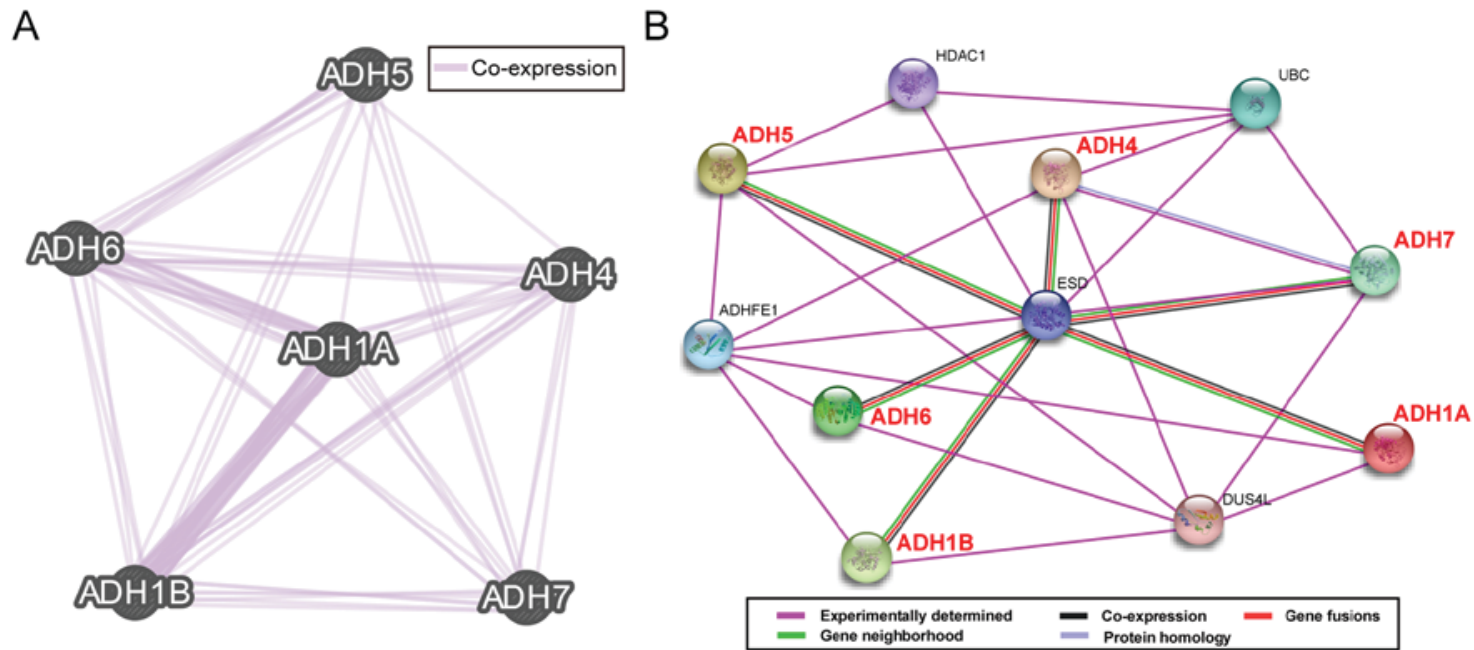

Figure 2. Gene and protein interaction networks of ADH genes. (A) Gene multiple association network integration algorithm and (B) protein-protein interaction networks. ADH5, alcohol dehydrogenase 5 (class III), $\chi$ polypeptide; ADH6, alcohol dehydrogenase 6 (class V); ADH4, alcohol dehydrogenase 4 (class II), $\pi$ polypeptide; ADH1A, alcohol dehydrogenase 1A (class I), $\alpha$ polypeptide; ADH1B, alcohol dehydrogenase 1B (class I), $\beta$ polypeptide; ADH7, alcohol dehydrogenase 7 (class IV), $\mu$ or $\sigma$ polypeptide; HDAC1, histone deacetylase 1; UBC, ubiquitin C; ESD, esterase D; ADHFE1, alcohol dehydrogenase, iron containing 1; DUS4L, dihydrouridine synthase 4 like.

209613_at (ADH1B; Fig. 5A-C), 206262_at (ADH1C; Fig. 6A-C), 231678_at (ADH4; Fig. 7A-C), 208848_at (ADH5; Fig. 8A-C), 214261_at (ADH6; Fig. 9A-C) and 21055_at (ADH7; Fig. 10A-C). Survival analysis suggested that, overall, patients with GC with a high expression of $A D H 1 A$ (log-rank $\mathrm{P}=0.043 ; \mathrm{HR}=0.79 ; 95 \% \mathrm{CI}$ : 0.64-0.99; Fig. 4A), $A D H 1 B$ (log-rank $\mathrm{P}=1.9 \times 10^{-5} ; \mathrm{HR}=0.65 ; 95 \% \mathrm{CI}: 0.53-0.79$; Fig. 5A) and $A D H 5$ (log-rank $\mathrm{P}=0.0011 ; \mathrm{HR}=0.73$; 95\% CI: 0.60-0.88; Fig. 8A) were significantly associated with a favorable prognosis, compared with those with a low expression of these genes. Similar results are also observed in $A D H 4$ (Fig. 7A) and $A D H 7$ (Fig. 10A), however the log-rank P-values did not reach statistical significance. Subgroup survival analysis of patients with intestinal-type GC demonstrated that high expression of $A D H 1 B$ (log-rank $\mathrm{P}=0.031$; HR=0.64; 95\% CI: 0.43-0.96; Fig. 5B) significantly decreased the risk of mortality, compared with patients with a low expression of this gene. Furthermore, the increased expression of $A D H 1 A$,
$A D H 1 C$ and $A D H 4$ also demonstrated a similar outcome, but with a non-significant log-rank P-values (Figs. 4B, 6B and 7B). Furthermore, the same analysis performed on subgroups of diffuse-type GC, additionally suggested that patients with GC with a high expression of $A D H 1 A$ (log-rank $\mathrm{P}=0.014 ; \mathrm{HR}=0.51 ; 95 \% \mathrm{CI}$ : 0.30-0.88; Fig. 4C), $A D H 1 B$ (log-rank $\mathrm{P}=0.04 ; \mathrm{HR}=0.53$; 95\% CI: 0.29-0.98; Fig. 5C), ADH4 (log-rank $\mathrm{P}=0.033 ; \mathrm{HR}=0.58 ; 95 \% \mathrm{CI}: 0.35-0.96$; Fig. 7C) and $A D H 6$ (log-rank $\mathrm{P}=0.037$; HR=0.59; 95\% CI: 0.35-0.97; Fig. 9C) demonstrated significantly decreased risk of mortality, compared with patients with low expression. In contrast, the high expression of $A D H 5$ (log-rank $\mathrm{P}=0.044$; $\mathrm{HR}=1.66$; 95\% CI: 1.01-2.74; Fig. 8C) was significantly associated with a poor prognosis for patients with diffuse-type GC compared with patients with a low expression of this gene.

In addition, the prognostic values of $\mathrm{ADH}$ genes in stratified sampling in distinct patient subgroups of GC were analyzed. 
A

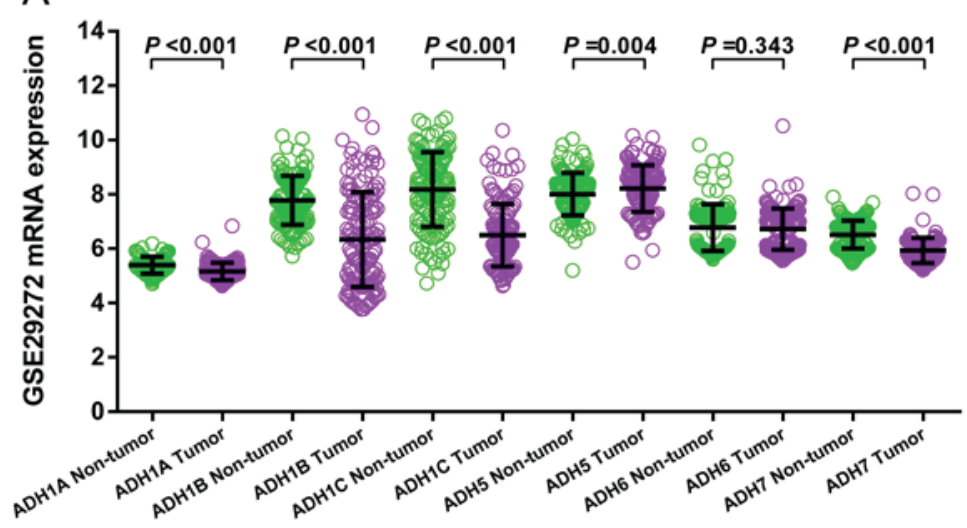

B

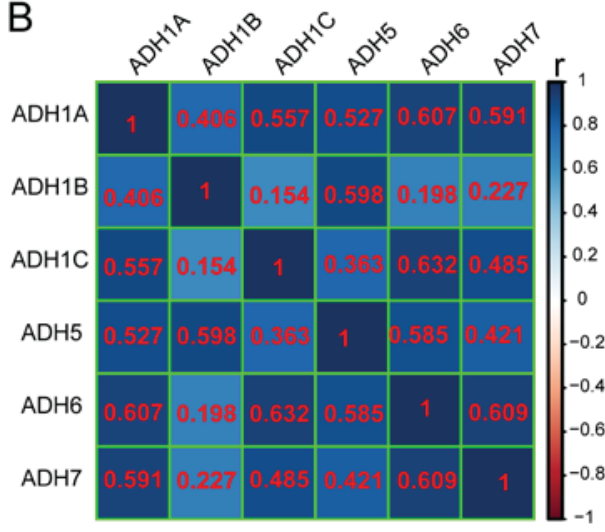

Figure 3. Comparison of the expression of ADH genes between GC tumor and adjacent non-tumor tissue and ADH gene co-expression analysis. (A) Scatter plot of the expression of ADH genes between tumor and adjacent non-tumor tissue in patients with GC. (B) Co-expression heat map of ADH genes (the numbers shown in red are the r-values of pearson correlation coefficient). GC, gastric cancer; ADH1A, alcohol dehydrogenase 1A (class I), $\alpha$ polypeptide; ADH1B, alcohol dehydrogenase 1B (class I), $\beta$ polypeptide; ADH1C, alcohol dehydrogenase $1 \mathrm{C}$ (class I), $\gamma$ polypeptide; ADH5, alcohol dehydrogenase 5 (class III), $\chi$ polypeptide; ADH6, alcohol dehydrogenase 6 (class V); ADH7, alcohol dehydrogenase 7 (class IV), $\mu$ or o polypeptide.
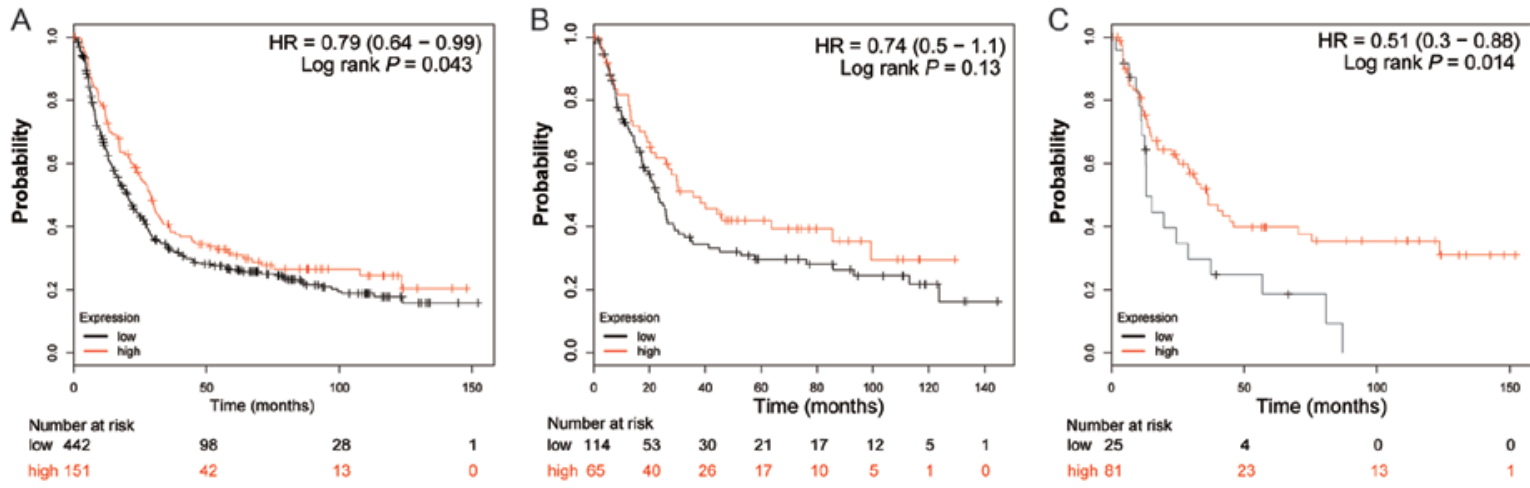

Figure 4. Prognostic value of ADHIA (207820_at) expression in the Kaplan-Meier plotter tool. (A) Kaplan-Meier survival curves for all patients with GC $(\mathrm{n}=593)$ with low and high expression of ADH1A. (B) Kaplan-Meier survival curves for patients with intestinal-type GC (n=179) with low and high expression of ADH1A. (C) Kaplan-Meier survival curves for patients with diffuse-type GC (n=106) with low and high expression of ADH1A. GC, gastric cancer; ADH1A, alcohol dehydrogenase 1A (class I), $\alpha$ polypeptide; HR, hazard ratio.

A

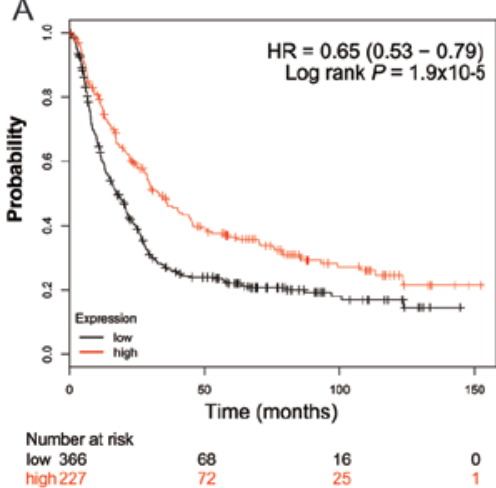

B

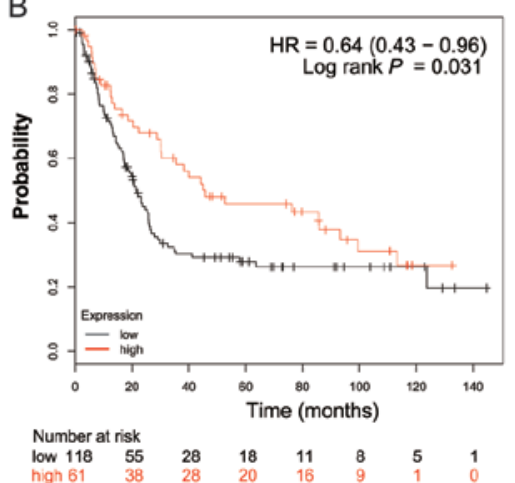

C

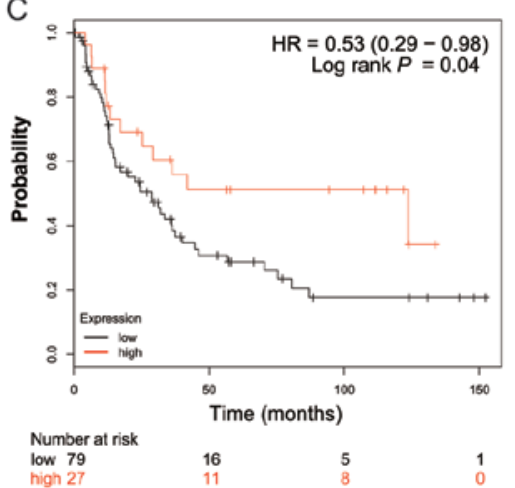

Figure 5. Prognostic value of $A D H 1 B$ (209613_at) expression in the Kaplan-Meier plotter tool. (A) Kaplan-Meier survival curves for all patients with GC ( $\mathrm{n}=593$ ) with low and high expression of $A D H 1 B$. (B) Kaplan-Meier survival curves for patients with intestinal-type GC ( $\mathrm{n}=179$ ) with low and high expression of $A D H 1 B$. (C) Kaplan-Meier survival curves for patients with diffuse-type GC ( $\mathrm{n}=106)$ with low and high expression of $A D H 1 B$. GC, gastric cancer; ADH1B, alcohol dehydrogenase 1B (class I), $\beta$ polypeptide; HR, hazard ratio.

Stratified analyses of patients with GC with different treatments are presented in Table I. It was observed that the high expression of ADH1A ( $\mathrm{P}=0.0095), A D H 1 B\left(\mathrm{P}=1.80 \times 10^{-6}\right)$,
ADHIC $(\mathrm{P}=0.0053), A D H 4(\mathrm{P}=0.037), A D H 5(\mathrm{P}=0.032)$ and $A D H 7(\mathrm{P}=0.035)$ significantly decreased the risk of mortality for patients with GC receiving 5-fluorouracil (5-FU)-based 

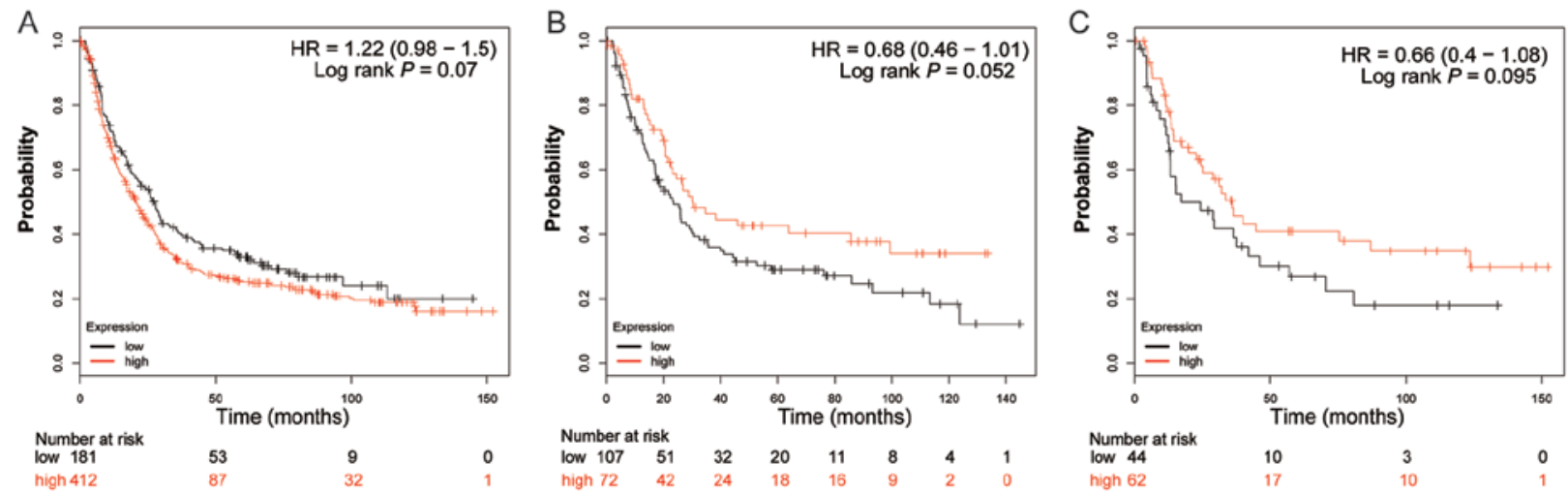

Figure 6. Prognostic value of ADH1C (206262_at) expression in the Kaplan-Meier plotter tool. (A) Kaplan-Meier survival curves for all patients with GC ( $\mathrm{n}=593$ ) with low and high expression of $A D H 1 C$. (B) Kaplan-Meier survival curves for patients with intestinal-type GC ( $\mathrm{n}=179$ ) with low and high expression of ADH1C. (C) Kaplan-Meier survival curves for patients with diffuse-type GC (n=106) with low and high expression of ADH1C. GC, gastric cancer; ADH1C, alcohol dehydrogenase 1C (class I), $\gamma$ polypeptide; HR, hazard ratio.
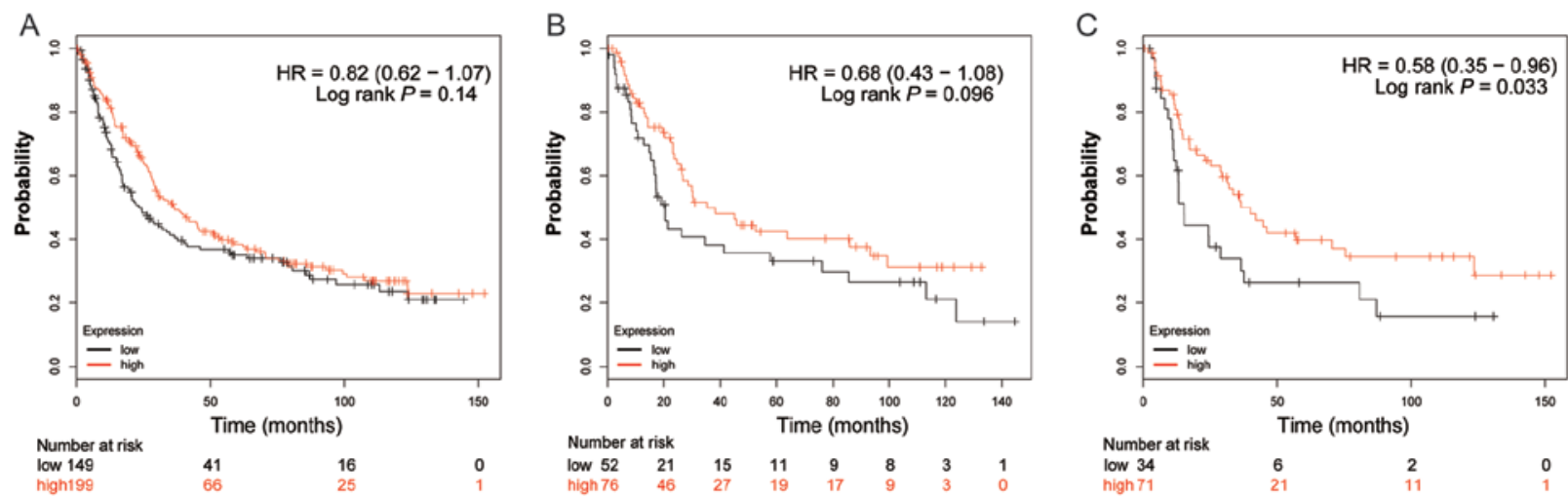

Figure 7. Prognostic value of $A D H 4$ (231678_at) expression in the Kaplan-Meier plotter tool. (A) Kaplan-Meier survival curves for all patients with GC (n=348) with low and high expression of $A D H 4$. (B) Kaplan-Meier survival curves for patients with intestinal-type GC (n=128) with low and high expression of $A D H 4$. (C) Kaplan-Meier survival curves for patients with diffuse-type GC (n=105) with low and high expression of ADH4. GC, gastric cancer; ADH4, alcohol dehydrogenase 4 (class II), $\pi$ polypeptide; HR, hazard ratio.
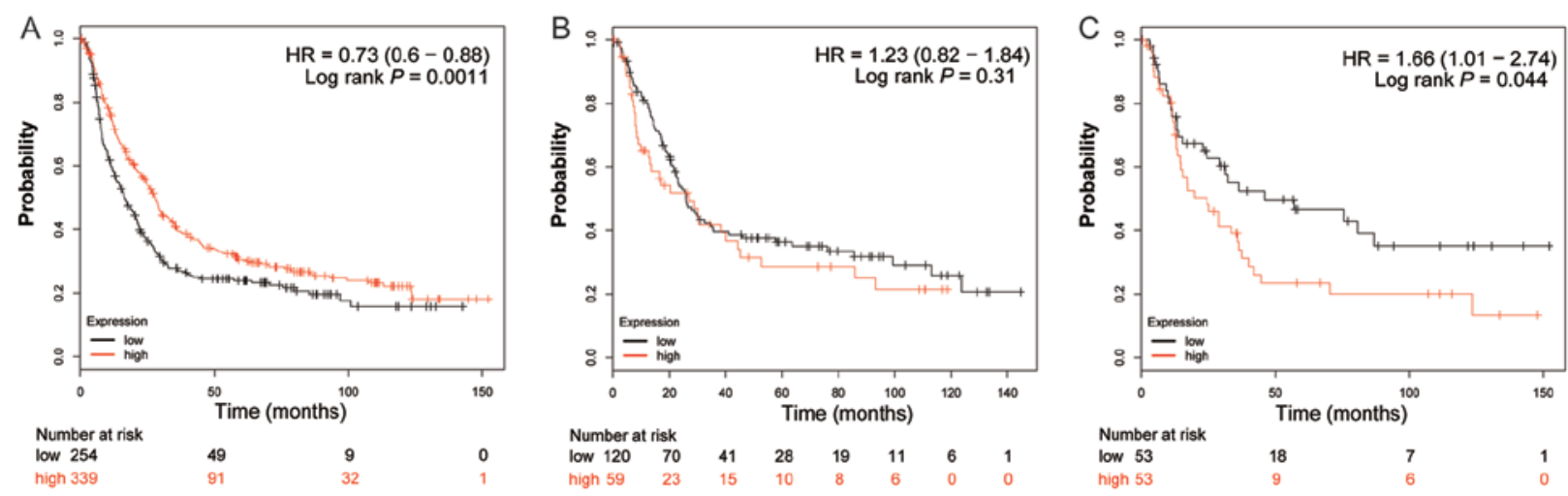

Figure 8. Prognostic value of ADH5 (208848_at) expression in the Kaplan-Meier plotter tool. (A) Kaplan-Meier survival curves for all patients with GC ( $\mathrm{n}=593$ ) with low and high expression of $A D H 5$. (B) Kaplan-Meier survival curves for patients with intestinal-type GC (n=179) with low and high expression of ADH5. (C) Kaplan-Meier survival curves for patients with diffuse-type GC ( $\mathrm{n}=106)$ with low and high expression of ADH5. GC, gastric cancer; ADH5, alcohol dehydrogenase 5 (class III), $\chi$ polypeptide; HR, hazard ratio.

adjuvant chemotherapy compared with patients with low expression of these genes. In contrast, high $A D H 6$ expression significantly increased the risk of mortality for patients with GC receiving 5-FU-based adjuvant chemotherapy compared with patients with low expression of these genes $(\mathrm{P}=0.043$;
Table I). The strata of patients with GC receiving surgery alone revealed that the high expression of $A D H 1 B$ significantly decreased the risk of mortality for patients with GC compared with low expression $(\mathrm{P}=0.0082)$, whereas no significant associations between any of the other ADH genes expression and 

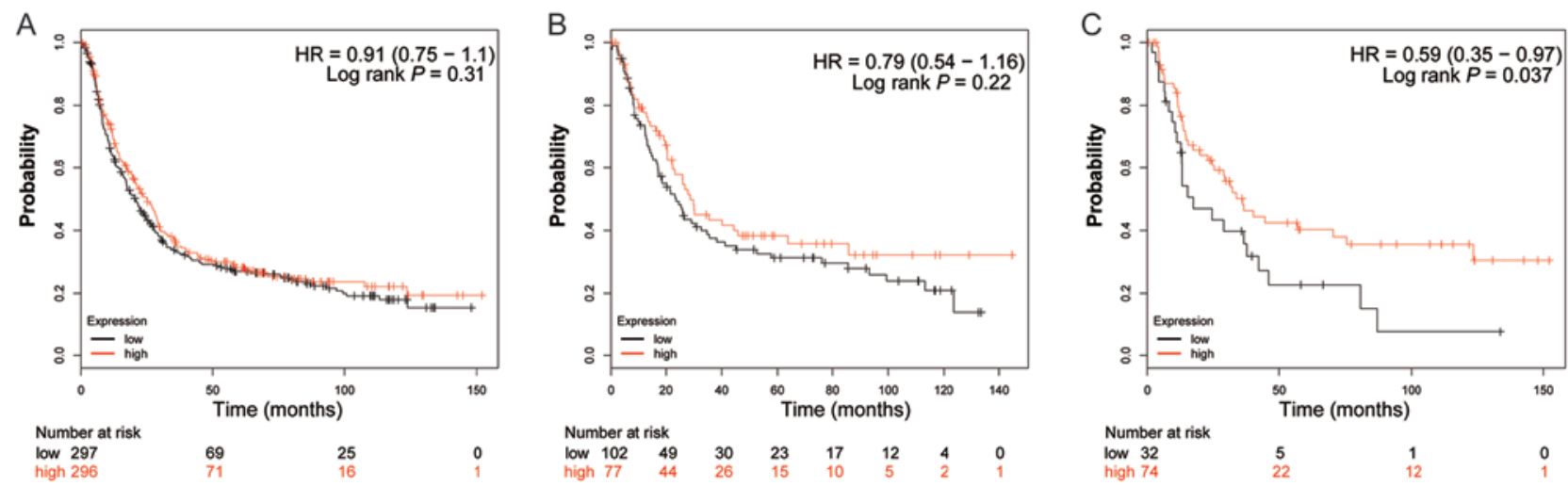

Figure 9. Prognostic value of $A D H 6$ (214261_at) expression in the Kaplan-Meier plotter tool. (A) Kaplan-Meier survival curves for all patients with GC (n=593) with low and high expression of $A D H 6$. (B) Kaplan-Meier survival curves for patients with intestinal-type $\mathrm{GC}(\mathrm{n}=179)$ with low and high expression of $A D H 6$. (C) Kaplan-Meier survival curves for patients with diffuse-type GC $(\mathrm{n}=106)$ with low and high expression of ADH6. GC, gastric cancer; ADH6, alcohol dehydrogenase 6 (class V); HR, hazard ratio.
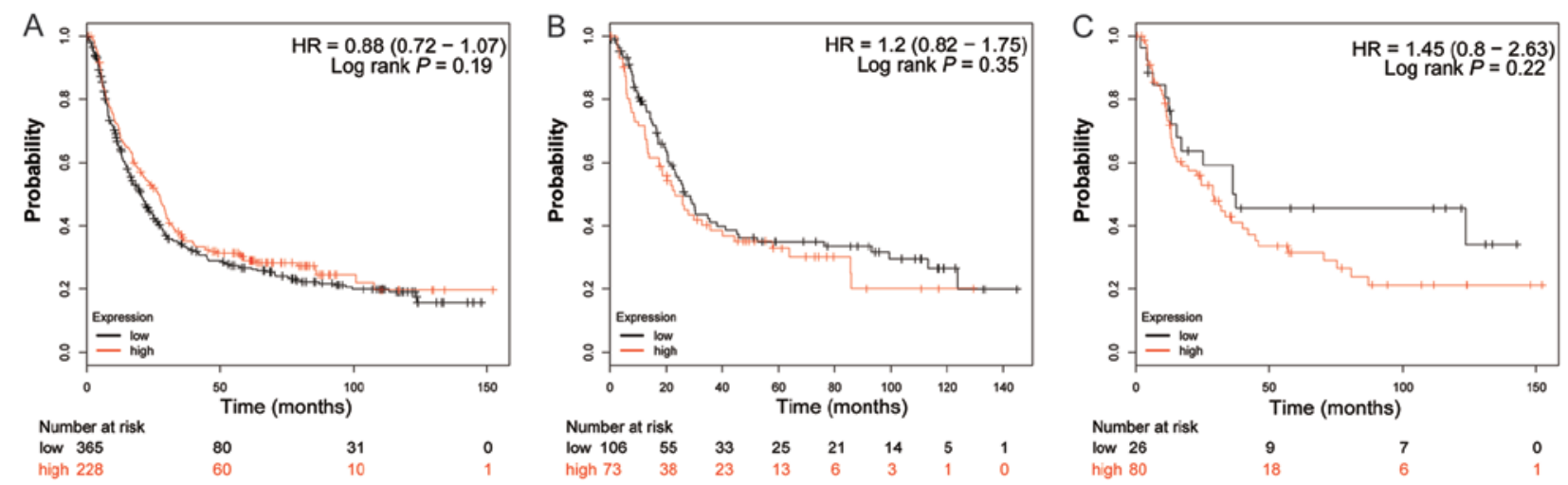

Figure 10. Prognostic value of $A D H 7$ (21055_at) expression in the Kaplan-Meier plotter tool. (A) Kaplan-Meier survival curves for all patients with GC (n=593) with low and high expression of $A D H 7$. (B) Kaplan-Meier survival curves for patients with intestinal-type $\mathrm{GC}(\mathrm{n}=179)$ with low and high expression of $A D H 7$. (C) Kaplan-Meier survival curves for patients with diffuse-type GC $(\mathrm{n}=106)$ with low and high expression of ADH7. GC, gastric cancer; ADH7, alcohol dehydrogenase 7 (class IV), $\mu$ or $\sigma$ polypeptide; HR, hazard ratio.

GC prognosis were identified in the present study following surgery alone.

Stratified analysis by HER2 status, presented in Table II, indicate that high expression of $A D H 1 B(\mathrm{P}=0.0013)$ and $A D H 5$ $(\mathrm{P}=0.0041)$ were significantly associated with a favorable prognosis in patients with HER2-negative GC. Similar results may also be observed with high expression of $A D H 1 A(\mathrm{P}=0.032)$ and $A D H 1 B(\mathrm{P}=0.0033)$ being significantly associated with a favorable prognosis in patients with GC with a positive HER2 status (Table II).

Stratified analysis by pathological grade, presented in Table III, indicate that the high expression of $A D H 1 C$ was significantly associated with the decreased risk of mortality for patients with GC with well-differentiated tumors $(\mathrm{P}=0.046)$ compared with low expression, whereas high $A D H 5$ expression was significantly associated with an increased risk of mortality compared with low expression $(\mathrm{P}=0.028)$. The stratified analysis in $\mathrm{GC}$ clinical stages suggests that high expression of ADHIA ( $\mathrm{P}=0.025)$, ADH4 $(\mathrm{P}=0.035)$, ADH5 $(\mathrm{P}=0.0059)$ and ADH6 $(\mathrm{P}=0.022)$ in stage 2 patients, and high expression of $A D H 5(\mathrm{P}=0.033)$ in stage 3 patients demonstrated a significantly increased risk of mortality compared with low expression (Table IV). In contrast, high expression of $A D H 7$ was significantly associated with a decreased risk of mortality in patients with stage $1 \mathrm{GC}(\mathrm{P}=0.028$; Table IV).

\section{Discussion}

$\mathrm{ADH}$ and ALDH are the most important enzymes for ethanol metabolism in vivo (31). Ethanol is initially metabolized by ADH isoenzymes to acetaldehyde, then the acetaldehyde is further metabolized to acetic acid using ALDH isoenzymes (32). GO enrichment analysis in the present study revealed that $\mathrm{ADH}$ genes are involved in ethanol oxidation, ADH and retinol dehydrogenase activity, alcohol metabolic and retinoid metabolic processes; consistent with what is already known about these genes $(33,34)$. KEGG analysis in the present study suggested that $\mathrm{ADH}$ genes were involved in retinol metabolism, drug metabolism via cytochrome P450 enzymes, metabolism of xenobiotics by cytochrome $\mathrm{P} 450$ and chemical carcinogenesis pathways. These results suggest that ADH genes are involved in ethanol, drug and toxic chemical redox metabolism processes in vivo. ADH isoenzymes include five class proteins that are encoded by seven genes. Class I ADH isoenzymes are encoded by $A D H 1 A, A D H 1 B$ and $A D H 1 C$, whilst class II ADH isoenzymes are encoded by $A D H 4$. Class III ADH, class IV ADH 
Table I. Associations between the high expression of ADH genes and different treatments received by patients with gastric cancer.

\begin{tabular}{|c|c|c|c|c|}
\hline Gene & Treatment & Cases, $\mathrm{n}$ & $\begin{array}{c}\text { Hazard ratio } \\
(95 \% \text { confidence interval) }\end{array}$ & $\begin{array}{c}\text { Log-rank } \\
\text { P-value }\end{array}$ \\
\hline \multirow[t]{2}{*}{$A D H 1 A$} & Surgery alone & 174 & $0.68(0.44-1.03)$ & 0.0660 \\
\hline & 5-FU-based adjuvant chemotherapy & 153 & $0.59(0.4-0.88)$ & 0.0095 \\
\hline \multirow[t]{2}{*}{$A D H 1 B$} & Surgery alone & 174 & $0.57(0.38-0.87)$ & 0.0082 \\
\hline & 5-FU-based adjuvant chemotherapy & 153 & $0.41(0.28-0.6)$ & $<0.0001$ \\
\hline \multirow[t]{2}{*}{$A D H 1 C$} & Surgery alone & 174 & $0.73(0.48-1.11)$ & 0.1400 \\
\hline & 5-FU-based adjuvant chemotherapy & 153 & $0.57(0.38-0.85)$ & 0.0053 \\
\hline \multirow[t]{2}{*}{ ADH4 } & Surgery alone & 174 & $0.76(0.5-1.15)$ & 0.2000 \\
\hline & 5-FU-based adjuvant chemotherapy & 34 & $0.39(0.16-0.97)$ & 0.0370 \\
\hline \multirow[t]{2}{*}{ ADH5 } & Surgery alone & 174 & $1.27(0.84-1.93)$ & 0.2500 \\
\hline & 5-FU-based adjuvant chemotherapy & 153 & $0.64(0.43-0.96)$ & 0.0320 \\
\hline \multirow[t]{2}{*}{ ADH6 } & Surgery alone & 174 & $1.23(0.8-1.91)$ & 0.3400 \\
\hline & 5-FU-based adjuvant chemotherapy & 153 & $1.48(1.01-2.16)$ & 0.0430 \\
\hline \multirow[t]{2}{*}{$A D H 7$} & Surgery alone & 174 & $1.34(0.8-2.24)$ & 0.2700 \\
\hline & 5-FU-based adjuvant chemotherapy & 153 & $0.66(0.45-0.97)$ & 0.0350 \\
\hline
\end{tabular}

ADH1A, alcohol dehydrogenase 1A (class I), $\alpha$ polypeptide; ADH1B, alcohol dehydrogenase 1B (class I), $\beta$ polypeptide; ADH1C, alcohol dehydrogenase 1C (class I), $\gamma$ polypeptide; ADH4, alcohol dehydrogenase 4 (class II), $\pi$ polypeptide; ADH5, alcohol dehydrogenase 5 (class III), $\chi$ polypeptide; ADH6, alcohol dehydrogenase 6 (class V); ADH7, alcohol dehydrogenase 7 (class IV), $\mu$ or $\sigma$ polypeptide; 5-FU, 5-fluorouracil.

Table II. Association between the high expression of ADH genes and the HER2 status of patients with gastric cancer.

\begin{tabular}{|c|c|c|c|c|}
\hline Gene & HER2 status & Cases, (n) & Hazard ratio ( $95 \%$ confidence interval) & Log-rank P-value \\
\hline \multirow[t]{2}{*}{$A D H 1 A$} & Negative & 298 & $0.78(0.59-1.03)$ & 0.0820 \\
\hline & Positive & 295 & $0.71(0.52-0.97)$ & 0.0320 \\
\hline \multirow[t]{2}{*}{$A D H 1 B$} & Negative & 298 & $0.61(0.45-0.83)$ & 0.0013 \\
\hline & Positive & 295 & $0.61(0.44-0.85)$ & 0.0033 \\
\hline \multirow[t]{2}{*}{$A D H 1 C$} & Negative & 298 & $1.19(0.9-1.58)$ & 0.2300 \\
\hline & Positive & 295 & $1.32(0.97-1.8)$ & 0.0790 \\
\hline \multirow[t]{2}{*}{ ADH4 } & Negative & 195 & $0.8(0.56-1.15)$ & 0.2200 \\
\hline & Positive & 153 & $0.77(0.51-1.16)$ & 0.2100 \\
\hline \multirow[t]{2}{*}{ ADH5 } & Negative & 298 & $0.67(0.51-0.88)$ & 0.0041 \\
\hline & Positive & 295 & $0.79(0.6-1.03)$ & 0.0830 \\
\hline \multirow[t]{2}{*}{ ADH6 } & Negative & 298 & $1.16(0.87-1.56)$ & 0.3100 \\
\hline & Positive & 295 & $0.8(0.59-1.08)$ & 0.1400 \\
\hline \multirow[t]{2}{*}{$A D H 7$} & Negative & 298 & $0.81(0.58-1.11)$ & 0.1900 \\
\hline & Positive & 295 & $0.77(0.58-1.02)$ & 0.0710 \\
\hline
\end{tabular}

HER2, human epidermal growth factor receptor 2; ADH1A, alcohol dehydrogenase 1A (class I), $\alpha$ polypeptide; ADH1B, alcohol dehydrogenase 1B (class I), $\beta$ polypeptide; ADH1C, alcohol dehydrogenase 1C (class I), $\gamma$ polypeptide; ADH4, alcohol dehydrogenase 4 (class II), $\pi$ polypeptide; ADH5, alcohol dehydrogenase 5 (class III), $\chi$ polypeptide; ADH6, alcohol dehydrogenase 6 (class V); ADH7, alcohol dehydrogenase 7 (class IV), $\mu$ or $\sigma$ polypeptide.

and class $\mathrm{V}$ ADH isoenzymes are encoded by $A D H 5, A D H 6$ and $A D H 7$, respectively $(35,36)$.

A previous study has reported that ADH isoenzymes possess diagnostic value in multiple malignant neoplasms and that ADH isoenzymes may be used as cancer biomarkers (37).
In addition, previous studies demonstrated a significant increase in the activity of serum class I ADH isoenzymes in patients with renal cell cancer (38), colorectal cancer (CRC) (12), endometrial cancer $(39)$, brain cancer $(40,41)$ and cervical cancer patients (42) compared with healthy patients, and demonstrate 
Table III. Association between the high expression of ADH genes and the pathological grades of patients with gastric cancer.

\begin{tabular}{|c|c|c|c|c|}
\hline Gene & Pathological grades & Cases (n) & $\begin{array}{c}\text { Hazard ratio } \\
(95 \% \text { confidence interval) }\end{array}$ & $\begin{array}{c}\text { Log-rank } \\
\text { P-value }\end{array}$ \\
\hline \multirow[t]{3}{*}{$A D H 1 A$} & Well differentiated & 32 & $0.42(0.14-1.24)$ & 0.1100 \\
\hline & Moderately differentiated & 67 & $0.68(0.32-1.46)$ & 0.3200 \\
\hline & Poorly differentiated & 165 & $0.7(0.46-1.05)$ & 0.0860 \\
\hline \multirow[t]{3}{*}{$A D H 1 B$} & Well differentiated & 32 & $0.67(0.26-1.73)$ & 0.4100 \\
\hline & Moderately differentiated & 67 & $0.56(0.28-1.12)$ & 0.0960 \\
\hline & Poorly differentiated & 165 & $0.79(0.51-1.22)$ & 0.2800 \\
\hline \multirow[t]{3}{*}{$A D H 1 C$} & Well differentiated & 32 & $0.39(0.15-1.02)$ & 0.0460 \\
\hline & Moderately differentiated & 67 & $0.66(0.3-1.45)$ & 0.3000 \\
\hline & Poorly differentiated & 165 & $1.35(0.9-2.03)$ & 0.1400 \\
\hline \multirow[t]{3}{*}{ ADH4 } & Well differentiated & 5 & NA & NA \\
\hline & Moderately differentiated & 67 & $0.77(0.4-1.48)$ & 0.4300 \\
\hline & Poorly differentiated & 121 & $0.68(0.42-1.11)$ & 0.1200 \\
\hline \multirow[t]{3}{*}{ ADH5 } & Well differentiated & 32 & $2.68(1.07-6.7)$ & 0.0280 \\
\hline & Moderately differentiated & 67 & $1.46(0.76-2.83)$ & 0.2500 \\
\hline & Poorly differentiated & 165 & $1.21(0.81-1.8)$ & 0.3500 \\
\hline \multirow[t]{3}{*}{ ADH6 } & Well differentiated & 32 & $1.37(0.46-4.06)$ & 0.5700 \\
\hline & Moderately differentiated & 67 & $0.63(0.3-1.33)$ & 0.2200 \\
\hline & Poorly differentiated & 165 & $1.41(0.94-2.1)$ & 0.0920 \\
\hline \multirow[t]{3}{*}{$A D H 7$} & Well differentiated & 32 & $2.45(0.82-7.31)$ & 0.0980 \\
\hline & Moderately differentiated & 67 & $0.56(0.29-1.07)$ & 0.0750 \\
\hline & Poorly differentiated & 165 & $0.81(0.54-1.22)$ & 0.3100 \\
\hline
\end{tabular}

ADH1A, alcohol dehydrogenase 1A (class I), $\alpha$ polypeptide; ADH1B, alcohol dehydrogenase 1B (class I), $\beta$ polypeptide; ADH1C, alcohol dehydrogenase 1C (class I), $\gamma$ polypeptide; ADH4, alcohol dehydrogenase 4 (class II), $\pi$ polypeptide; ADH5, alcohol dehydrogenase 5 (class III), $\chi$ polypeptide; ADH6, alcohol dehydrogenase 6 (class V); ADH7, alcohol dehydrogenase 7 (class IV), $\mu$ or $\sigma$ polypeptide; NA, not available.

a diagnostic value in these cancer types. Similarly, class III isoenzymes also demonstrate a diagnostic value in pancreatic cancer (43), whereas, class IV ADH isoenzymes show a diagnostic value in GC (14) and esophageal cancer (13). A significant increase in total ADH isoenzymes was additionally observed in the serum of patients with these cancer types. In addition, class I ADH isoenzymes are upregulated in liver cancer (44), esophageal cancer (45) and bladder cancer (46), however, the diagnostic value of class I ADH in these cancer types requires further exploration. Similarly, as in the serum results of patients with malignant neoplasms, ADH isoenzyme activity has been identified in tumor tissues (37). Studies have additionally reported that class I ADH isoenzymes are significantly increased in the tumor tissue of cervical cancer (47), ovarian cancer (48), endometrial cancer (49), brain cancer (50), liver cancer $(44,51)$, CRC $(52,53)$ and renal cell carcinoma (54) compared with healthy tissue, whereas ALDH isoenzymes in these cancer types did not demonstrate a statistically significant difference between cancer and healthy tissue. However, a downregulation of class I ADH was observed in breast cancer tissues (55), whereas the expression of other ADH isoenzymes remained unchanged. ADH and ALDH are the most important enzymes for ethanol metabolism, and acetaldehyde is a product of ADH metabolized alcohol and ALDH further metabolizes it to acetic acid (31). As is well known, acetaldehyde is the most toxic ethanol metabolite and a cancer-causing agent (7). The metabolism of acetaldehyde depends on the balance between ADH and ALDH; therefore, these results suggest the activity of ADH and an unchanged level of ALDH may result in the accumulation of acetaldehyde, that may result in tumorigenesis. In addition, other classes of ADH isoenzyme upregulation have additionally been observed in other cancer types, including class III ADH for pancreatic cancer tissue (56) and class III ADH for esophageal cancer (57). In addition, a marked upward trend of ADH IV was exhibited in patients with GC according to the advancement of tumor progression, and the other isoenzymes additionally revealed an upward trend in accordance with tumor progression; however, the changes did not demonstrate a statistical significance (14). Consequently, there was an increased trend of total ADH activity according to GC progression (14). These results suggest that disturbances of ADH isoenzyme activity serve a notable function in alcohol-associated neoplasms, and may be potential diagnostic biomarkers. In the present study, $\mathrm{ADH}$ isoenzyme expression between GC tumor and adjacent non-tumor tissues was further analyzed, and revealed that the mRNA expression level of $A D H 1 A, A D H 1 B, A D H 1 C$ and $A D H 7$ were significantly downregulated in tumor tissues compared with non-tumor tissues, whereas ADH5 was significantly upregulated in tumor tissues compared with 
Table IV. Association between the high expression of ADH genes and the clinical stages of patients with gastric cancer.

\begin{tabular}{|c|c|c|c|c|}
\hline Gene & Clinical stages & Cases (n) & Hazard ratio ( $95 \%$ confidence interval) & Log-rank P-value \\
\hline \multirow[t]{4}{*}{$A D H 1 A$} & 1 & 39 & $1.76(0.56-5.5)$ & 0.3200 \\
\hline & 2 & 49 & $4.6(1.07-19.77)$ & 0.0250 \\
\hline & 3 & 217 & $1.15(0.83-1.6)$ & 0.3900 \\
\hline & 4 & 74 & $0.62(0.36-1.07)$ & 0.0840 \\
\hline \multirow[t]{4}{*}{$A D H 1 B$} & 1 & 39 & $0.56(0.17-1.84)$ & 0.3300 \\
\hline & 2 & 49 & $3.02(0.89-10.25)$ & 0.0620 \\
\hline & 3 & 217 & $0.85(0.59-1.22)$ & 0.3800 \\
\hline & 4 & 74 & $1.23(0.7-2.16)$ & 0.4700 \\
\hline \multirow[t]{4}{*}{$A D H 1 C$} & 1 & 39 & $2.41(0.65-8.88)$ & 0.1700 \\
\hline & 2 & 49 & $0.62(0.27-1.44)$ & 0.2700 \\
\hline & 3 & 217 & $1.21(0.85-1.71)$ & 0.2800 \\
\hline & 4 & 74 & $0.75(0.43-1.31)$ & 0.3100 \\
\hline \multirow[t]{4}{*}{ ADH4 } & 1 & 34 & $2.91(0.84-10.15)$ & 0.0790 \\
\hline & 2 & 44 & $2.78(1.03-7.51)$ & 0.0350 \\
\hline & 3 & 109 & $1.45(0.89-2.38)$ & 0.1400 \\
\hline & 4 & 66 & $0.72(0.37-1.39)$ & 0.3200 \\
\hline \multirow[t]{4}{*}{ ADH5 } & 1 & 39 & $0.45(0.14-1.46)$ & 0.1700 \\
\hline & 2 & 49 & $3.19(1.33-7.64)$ & 0.0059 \\
\hline & 3 & 217 & $1.43(1.03-1.99)$ & 0.0330 \\
\hline & 4 & 74 & $1.56(0.85-2.87)$ & 0.1500 \\
\hline \multirow[t]{4}{*}{ ADH6 } & 1 & 39 & $2.29(0.63-8.35)$ & 0.2000 \\
\hline & 2 & 49 & $2.7(1.12-6.51)$ & 0.0220 \\
\hline & 3 & 217 & $0.89(0.61-1.28)$ & 0.5100 \\
\hline & 4 & 74 & $0.59(0.29-1.18)$ & 0.1300 \\
\hline \multirow[t]{4}{*}{$A D H 7$} & 1 & 39 & $0.74(0.94-58.3)$ & 0.0280 \\
\hline & 2 & 49 & $0.56(0.23-1.33)$ & 0.1800 \\
\hline & 3 & 217 & $0.85(0.59-1.23)$ & 0.3900 \\
\hline & 4 & 74 & $0.69(0.37-1.27)$ & 0.2300 \\
\hline
\end{tabular}

ADH1A, alcohol dehydrogenase 1A (class I), $\alpha$ polypeptide; ADH1B, alcohol dehydrogenase 1B (class I), $\beta$ polypeptide; ADH1C, alcohol dehydrogenase 1C (class I), $\gamma$ polypeptide; ADH4, alcohol dehydrogenase 4 (class II), $\pi$ polypeptide; ADH5, alcohol dehydrogenase 5 (class III), $\chi$ polypeptide; ADH6, alcohol dehydrogenase 6 (class V); ADH7, alcohol dehydrogenase 7 (class IV), $\mu$ or $\sigma$ polypeptide.

non-tumor tissues. The comparison of tumor and adjacent non-tumor tissues suggests that the dysregulation of $A D H 1 A$, $A D H 1 B, A D H 1 C, A D H 5$ and $A D H 7$ were associated with tumorigenesis in GC.

The diagnostic value of $\mathrm{ADH}$ isoenzymes has been investigated in multiple cancer types, particularly in studies by Jelski et al and Orywal and Szmitkowski (14,37). These previous studies reveal $\mathrm{ADH}$ isoenzyme activity in malignant neoplasms, particularly for alcohol-associated neoplasms. However, the prognostic values of these isoenzymes have rarely been reported in previous studies. A study by Wei et al (11) demonstrated that $A D H 4$ mRNA and protein expression in hepatocellular carcinoma (HCC) was significantly downregulated in tumor tissues compared with adjacent non-tumor tissues. High $A D H 4$ expression was significantly associated with a favorable prognosis and may be a potential prognostic marker for patients with HCC (11). The downregulation of $\mathrm{ADH}$ genes may additionally be revealed in hepatitis $\mathrm{B}$
(HBV)-associated HCC tumor tissue, and the high expression of $A D H 1 A, A D H 1 C, A D H 5$ and $A D H 6$ exhibit protective effects in patients with $\mathrm{HBV}$-associated HCC (58). The genetic variation of $\mathrm{ADH}$ genes has additionally been reported to be involved in the association between $\mathrm{ADH}$ polymorphisms and cancer survival. A study by Li et al (59) demonstrated that the genetic variation of $A D H 1 B$-rs1229984 was associated with laryngeal cancer overall survival (OS), and that the genetic algorithm genotype of rs1229984 decreased the risk of mortality in patients with laryngeal cancer and may be a prognostic indicator. The survival analysis performed in the present study demonstrated that the high expression of $A D H 1 A, A D H 1 B$ and $A D H 5$ were associated with a significantly decreased risk of mortality in all patients with GC. Furthermore, a similar effect was observed for $A D H 1 B$ in patients with intestinal-type GC and $A D H 1 A, A D H 1 B, A D H 4$ and $A D H 6$ for patients with diffuse-type GC. The results of the present study were consistent with those of a previous study (11). However, 
paradoxically, the present study additionally observed that the high expression of $A D H 5$ in patients with diffuse-type GC exhibit a poor prognosis, and $A D H 5$ high expression in $\mathrm{GC}$ tumor tissues appears to be more consistent with the performance of an oncogene.

The majority of highly expressed ADH genes revealed a protective effect in patients with GC receiving 5-FU-based adjuvant chemotherapy, these results were consistent with the pathway enrichment analysis that indicated that ADH genes were involved in drug metabolism via the cytochrome P450 pathway. This is potentially a consequence of $\mathrm{ADH}$ participation in drug metabolism and serves a function in the anticarcinogenic response, however this assumption requires further investigation. It was additionally observed that $A D H 6$ is associated with a significantly increased risk for patients with GC receiving 5-FU-based adjuvant chemotherapy in univariate stratification analysis. Due to a lack of data from previous studies and multivariate analysis in the present study, further studies are required in order to verify the association between $A D H 6$ and GC prognosis. In addition, $A D H 1 B$ also demonstrated protective effects in patients with GC who received surgery alone.

Overexpression of HER2 is associated with poor GC prognosis and associated with Lauren classification, tumor size, lymph node and World Health Organization classification (60). However, to the best of our knowledge, there are no reports on the association between HER2 and ADH isoenzymes. The results of the present study revealed that high expression of $A D H 1 A$ and $A D H 1 B$ were associated with a significantly decreased risk of mortality in patients with HER2-positive GC, in addition to high $A D H 1 B$ and $A D H 5$ for patients with HER2-negative GC.

There were limitations in the present study that need to be recognized. First, the clinical information from the GEO database was not comprehensive; therefore, this study evaluates the association between ADH genes expression and OS based on univariate survival analysis. Second, the sample size of this study was not large enough to validate the impact of a number of strata with a small sample size on OS in the stratified analysis. Third, the results of the present study reveal a significantly positive association between the mRNA expression of all ADH genes with each other, and consequently, individual $\mathrm{ADH}$ genes may have complex interactions and finally have a joint effect on the outcome of patients with GC. Unfortunately, the KM-plotter tool is unable to analyze the joint effect of ADH gene expression in GC prognosis.

Despite these limitations, to the best of our knowledge, the present study is the first study to investigate the associations between $\mathrm{ADH}$ genes expression and $\mathrm{OS}$ in patients with GC, in addition to the prognostic values among the different strata of GC. These results provide insight into the function of $\mathrm{ADH}$ genes in clinical outcomes of cancer and may demonstrate a clinical utility for prognosis prediction and decision-making in GC management.

In summary, the results of the present study demonstrated that the high expression of $A D H 1 A$ and $A D H 1 B$ mRNA were associated with favorable prognosis in patients with intestinal-type and diffuse-type GC, whereas the other ADH genes either resulted in a different OS between these two types of GC or did not demonstrate a statistically significant difference in the OS between the groups. Therefore, the prognostic value of other $\mathrm{ADH}$ genes requires further investigation.
The results of the present study suggest that $A D H 1 A$ and $A D H 1 B$ may be potential prognostic biomarkers of GC. Owing to the small sample size and inability to perform multivariate analysis, further well-designed and larger sample size studies are necessary in order to validate these results.

\section{Acknowledgements}

The present study was supported in part by the National Nature Science Foundation of China (grant no. 81360448), the Innovation Project of Guangxi Graduate Education (2017), the Self-raised Scientific Research Fund of the Health and Family Planning Commission of the Guangxi Zhuang Autonomous Region (grant no. Z2015198) and the Nanning Scientific Research and Technology Development Project (Key Research and Development Plan; grant no. 20173018-3). The authors thank the contributors of the Kaplan-Meier plotter for sharing their data on open access.

\section{Competing interests}

The authors declare that they have no competing interests.

\section{References}

1. Chen W, Zheng R, Baade PD, Zhang S, Zeng H, Bray F, Jemal A, Yu XQ and He J: Cancer statistics in China, 2015. CA Cancer J Clin 66: 115-132, 2016.

2. Torre LA, Bray F, Siegel RL, Ferlay J, Lortet-Tieulent J and Jemal A: Global cancer statistics, 2012. CA Cancer J Clin 65: 87-108, 2015.

3. Zeng H, Zheng R, Guo Y, Zhang S, Zou X, Wang N, Zhang L, Tang J, Chen J, Wei K, et al: Cancer survival in China, 2003-2005: A population-based study. Int J Cancer 136: 1921-1930, 2015.

4. Chen MJ, Chiou YY, Wu DC and Wu SL: Lifestyle habits and gastric cancer in a hospital-based case-control study in taiwan. Am J Gastroenterol 95: 3242-3249, 2000.

5. Bujanda L: The effects of alcohol consumption upon the gastrointestinal tract. Am J Gastroenterol 95: 3374-3382, 2000.

6. Torre LA, Sauer AM, Chen MS Jr, Kagawa-Singer M, Jemal A and Siegel RL: Cancer statistics for asian americans, native hawaiians, and pacific islanders, 2016: Converging incidence in males and females. CA Cancer J Clin 66: 182-202, 2016.

7. Boffetta $P$ and Hashibe M: Alcohol and cancer. Lancet Oncol 7: 149-156, 2006.

8. Seitz HK and Stickel F: Molecular mechanisms of alcoholmediated carcinogenesis. Nat Rev Cancer 7: 599-612, 2007.

9. Hashibe M, McKay JD, Curado MP, Oliveira JC, Koifman S, Koifman R, Zaridze D, Shangina O, Wünsch-Filho V, Eluf-Neto J, et al: Multiple ADH genes are associated with upper aerodigestive cancers. Nat Genet 40: 707-709, 2008.

10. Wu C, Kraft P, Zhai K, Chang J, Wang Z, Li Y, Hu Z, He Z, Jia W, Abnet CC, et al: Genome-wide association analyses of esophageal squamous cell carcinoma in chinese identify multiple susceptibility loci and gene-environment interactions. Nat Genet 44: 1090-1097, 2012.

11. Wei RR, Zhang MY, Rao HL, Pu HY, Zhang HZ and Wang HY: Identification of ADH4 as a novel and potential prognostic marker in hepatocellular carcinoma. Med Oncol 29: 2737-2743, 2012.

12. Jelski W, Mroczko B and Szmitkowski M: The diagnostic value of alcohol dehydrogenase (ADH) isoenzymes and aldehyde dehydrogenase (ALDH) measurement in the sera of colorectal cancer patients. Dig Dis Sci 55: 2953-2957, 2010.

13. Jelski W, Laniewska-Dunaj M, Niklinski J, Kozlowski M, Laudanski J and Szmitkowski M: The alcohol dehydrogenase isoenzyme (ADH IV) as a candidate tumour marker of esophageal cancer. Acta Biochim Pol 60: 489-493, 2013.

14. Jelski W, Orywal K, Laniewska M and Szmitkowski M: The diagnostic value of alcohol dehydrogenase (ADH) isoenzymes and aldehyde dehydrogenase (ALDH) measurement in the sera of gastric cancer patients. Clin Exp Med 10: 215-219, 2010. 
15. Jelski W and Szmitkowski M: Alcohol dehydrogenase (ADH) and aldehyde dehydrogenase (ALDH) in the cancer diseases. Clin Chim Acta 395: 1-5, 2008.

16. Lánczky A, Nagy Á, Bottai G, Munkácsy G, Szabó A, Santarpia L and Győrffy B: miRpower: A web-tool to validate survival-associated miRNAs utilizing expression data from 2178 breast cancer patients. Breast Cancer Res Treat 160: 439-446, 2016.

17. Györffy B, Lanczky A, Eklund AC, Denkert C, Budczies J, Li Q and Szallasi Z: An online survival analysis tool to rapidly assess the effect of 22,277 genes on breast cancer prognosis using microarray data of 1,809 patients. Breast Cancer Res Treat 123: 725-731, 2010.

18. Gyorffy B, Lanczky A and Szallasi Z: Implementing an online tool for genome-wide validation of survival-associated biomarkers in ovarian-cancer using microarray data from 1287 patients. Endocr Relat Cancer 19: 197-208, 2012.

19. Gyorffy B, Surowiak P, Budczies J and Lanczky A: Online survival analysis software to assess the prognostic value of biomarkers using transcriptomic data in non-small-cell lung cancer. PLoS One 8: e82241, 2013.

20. Szász AM, Lánczky A, Nagy Á, Förster S, Hark K, Green JE, Boussioutas A, Busuttil R, Szabó A and Győrffy B: Cross-validation of survival associated biomarkers in gastric cancer using transcriptomic data of 1,065 patients. Oncotarget 7 : 49322-49333, 2016

21. Li K, Guo X, Wang Z, Li X, Bu Y, Bai X, Zheng L and Huang Y: The prognostic roles of ALDH1 isoenzymes in gastric cancer. Onco Targets Ther 9: 3405-3414, 2016.

22. Dennis G Jr, Sherman BT, Hosack DA, Yang J, Gao W, Lane HC and Lempicki RA: DAVID: Database for annotation, visualization, and integrated discovery. Genome Biol 4: P3, 2003.

23. Warde-Farley D, Donaldson SL, Comes O, Zuberi K, Badrawi R, Chao P, Franz M, Grouios C, Kazi F, Lopes CT, et al: The GeneMANIA prediction server: Biological network integration for gene prioritization and predicting gene function. Nucleic Acids Res 38: W214-220, 2010.

24. Mostafavi S, Ray D, Warde-Farley D, Grouios C and Morris Q GeneMANIA: A real-time multiple association network integration algorithm for predicting gene function. Genome Biol 9: S4, 2008

25. Szklarczyk D, Franceschini A, Wyder S, Forslund K, Heller D, Huerta-Cepas J, Simonovic M, Roth A, Santos A, Tsafou KP, et al: STRING v10: Protein-protein interaction networks, integrated over the tree of life. Nucleic Acids Res 43: D447-452, 2015 .

26. von Mering C, Huynen M, Jaeggi D, Schmidt S, Bork P and Snel B: STRING: A database of predicted functional associations between proteins. Nucleic Acids Res 31: 258-261, 2003.

27. Sobin LH, Gospodarowicz MK and Wittekind CH; International Union against Cancer: TNM classification of malignant tumours. 7th edition. West Sussex, Chichester, UK, 2009.

28. Lauren P: The two histological main types of gastric carcinoma: Diffuse and so-called intestinal-type carcinoma. an attempt at a histo-clinical classification. Acta Pathol Microbiol Scand 64 $31-49,1965$.

29. Wang G, Hu N, Yang HH, Wang L, Su H, Wang C, Clifford R, Dawsey EM, Li JM, Ding T, et al: Comparison of global gene expression of gastric cardia and noncardia cancers from a high-risk population in china. PLoS One 8: e63826, 2013.

30. R Development Core Team: R: A language and environment for statistical computing. R Foundation for Statistical Computing, Vienna, 2008

31. Druesne-Pecollo N, Tehard B, Mallet Y, Gerber M, Norat T, Hercberg $S$ and Latino-Martel P: Alcohol and genetic polymorphisms: Effect on risk of alcohol-related cancer. Lancet Oncol 10: 173-180, 2009.

32. Klyosov AA: Kinetics and specificity of human liver aldehyde dehydrogenases toward aliphatic, aromatic, and fused polycyclic aldehydes. Biochemistry 35: 4457-4467, 1996.

33. Crabb DW, Bosron WF and Li TK: Ethanol metabolism Pharmacol Ther 34: 59-73, 1987.

34. Seitz HK and Oneta CM: Gastrointestinal alcohol dehydrogenase Nutr Rev 56: 52-60, 1998.

35. Holmes RS: Alcohol dehydrogenases: A family of isozymes with differential functions. Alcohol Alcohol Suppl 2: 127-130, 1994.

36. Holmes R: Alcohol dehydrogenases: Gene multiplicity and differential functions of five classes of isozymes. Drug Alcohol Rev 12: 99-110, 1993.

37. Orywal K and Szmitkowski M: Alcohol dehydrogenase and aldehyde dehydrogenase in malignant neoplasms. Clin Exp Med 17: 131-139, 2017.
38. Orywal K, Jelski W, Werel T and Szmitkowski M: The diagnostic significance of serum alcohol dehydrogenase isoenzymes and aldehyde dehydrogenase activity in renal cell cancer patients. Exp Mol Pathol 100: 416-420, 2016

39. Orywal K, Jelski W, Zdrodowski M and Szmitkowski M: The diagnostic value of alcohol dehydrogenase isoenzymes and aldehyde dehydrogenase measurement in the sera of patients with endometrial cancer. Anticancer Res 33: 3725-3730, 2013.

40. Jelski W, Laniewska-Dunaj M, Orywal K, Kochanowicz J, Rutkowski R and Szmitkowski M: The diagnostic value of alcohol dehydrogenase (ADH) isoenzymes and aldehyde dehydrogenase $(\mathrm{ALDH})$ measurement in the sera of patients with brain tumor. Arch Med Sci 13: 346-352, 2017.

41. Jelski W, Laniewska-Dunaj M, Orywal K, Kochanowicz J, Rutkowski R and Szmitkowski M: The activity of alcohol dehydrogenase (ADH) isoenzymes and aldehyde dehydrogenase $(A L D H)$ in the sera of patients with brain cancer. Neurochem Res 39: 2313-2318, 2014.

42. Orywal K, Jelski W, Zdrodowski M and Szmitkowski M: The diagnostic value of alcohol dehydrogenase isoenzymes and aldehyde dehydrogenase measurement sera of cervical cancer patients. Anticancer Res 36: 2265-2269, 2016.

43. Jelski W, Kutylowska E, Laniewska-Dunaj $M$ and Szmitkowski M: Alcohol dehydrogenase (ADH) and aldehyde dehydrogenase (ALDH) as candidates for tumor markers in patients with pancreatic cancer. J Gastrointestin Liver Dis 20: 255-259, 2011.

44. Jelski W, Zalewski B and Szmitkowski M: Alcohol dehydrogenase (ADH) isoenzymes and aldehyde dehydrogenase $(\mathrm{ALDH})$ activity in the sera of patients with liver cancer. J Clin Lab Anal 22: 204-209, 2008.

45. Jelski W, Kozlowski M, Laudanski J, Niklinski J and Szmitkowski M: Alcohol dehydrogenase isoenzymes and aldehyde dehydrogenase activity in the sera of patients with esophageal cancer. Clin Exp Med 9: 131-137, 2009.

46. Orywal K, Jelski W, Werel T and Szmitkowski M: The activity of class I, II, III and IV alcohol dehydrogenase isoenzymes and aldehyde dehydrogenase in the sera of bladder cancer patients. Acta Biochim Pol 64: 81-84, 2017.

47. Orywal K, Jelski W, Zdrodowski M and Szmitkowski M: The activity of class I, II, III and IV alcohol dehydrogenase isoenzymes and aldehyde dehydrogenase in cervical cancer. Clin Biochem 44: 1231-1234, 2011.

48. Orywal K, Jelski W, Zdrodowski M and Szmitkowski M: The activity of class I, II, III and IV alcohol dehydrogenase isoenzymes and aldehyde dehydrogenase in ovarian cancer and ovarian cysts. Adv Med Sci 58: 216-220, 2013.

49. Orywal K, Jelski W, Zdrodowski M and Szmitkowski M: The activity of class I, II, III, and IV alcohol dehydrogenase isoenzymes and aldehyde dehydrogenase in endometrial cancer. J Clin Lab Anal 24: 334-339, 2010.

50. Laniewska-Dunaj M, Jelski W, Orywal K, Kochanowicz J, Rutkowski R and Szmitkowski M: The activity of class I, II, III and IV of alcohol dehydrogenase (ADH) isoenzymes and aldehyde dehydrogenase (ALDH) in brain cancer. Neurochem Res 38: 1517-1521, 2013.

51. Jelski W, Zalewski B and Szmitkowski M: The activity of class I, II, III, and IV alcohol dehydrogenase (ADH) isoenzymes and aldehyde dehydrogenase (ALDH) in liver cancer. Dig Dis Sci 53: 2550-2555, 2008 .

52. Jelski W, Zalewski B, Chrostek L and Szmitkowski M: Alcohol dehydrogenase $(\mathrm{ADH})$ isoenzymes and aldehyde dehydrogenase (ALDH) activity in the sera of patients with colorectal cancer. Clin Exp Med 7: 154-157, 2007.

53. Jelski W, Zalewski B, Chrostek L and Szmitkowski M: The activity of class I, II, III, and IV alcohol dehydrogenase isoenzymes and aldehyde dehydrogenase in colorectal cancer. Dig Dis Sci 49: 977-981, 2004.

54. Orywal K, Jelski W, Werel T and Szmitkowski M: The activity of class I, II, III and IV alcohol dehydrogenase isoenzymes and aldehyde dehydrogenase in renal cell carcinoma. Exp Mol Pathol 98: 403-406, 2015.

55. Jelski W, Chrostek L, Szmitkowski M and Markiewicz W: The activity of class I, II, III and IV alcohol dehydrogenase isoenzymes and aldehyde dehydrogenase in breast cancer. Clin Exp Med 6: 89-93, 2006

56. Jelski W, Chrostek L and Szmitkowski M: The activity of class I, II, III, and IV of alcohol dehydrogenase isoenzymes and aldehyde dehydrogenase in pancreatic cancer. Pancreas 35 : 142-146, 2007 
57. Jelski W, Kozlowski M, Laudanski J, Niklinski J and Szmitkowski M: The activity of class I, II, III, and IV alcohol dehydrogenase (ADH) isoenzymes and aldehyde dehydrogenase (ALDH) in esophageal cancer. Dig Dis Sci 54: 725-730, 2009.

58. Shang L, Zhu G, Su H, Chen B, Ye X, Chen X, Xiao K, Li L, Peng $M$ and Peng T: Identification of alcohol dehydrogenase as a potential prognostic marker in HBV-related hepatocellular carcinoma. Int J Clin Exp Med 10: 4457-4472, 2017.

59. Li D, Zhang R, Jin T, He N, Ren L, Zhang Z, Zhang Q, Xu R, Tao H, Zeng $\mathrm{G}$ and Gao J: ADH1B and CDH1 polymorphisms predict prognosis in male patients with non-metastatic laryngeal cancer. Oncotarget 7: 73216-73228, 2016.
60. Jiang W, Jin Z, Zhou F, Cui J, Wang L and Wang L: High co-expression of $\mathrm{Sp} 1$ and HER-2 is correlated with poor prognosis of gastric cancer patients. Surg Oncol 24: 220-225, 2015.

This work is licensed under a Creative Commons Attribution-NonCommercial-NoDerivatives 4.0 International (CC BY-NC-ND 4.0) License. 